\title{
Rassal Etkiler Multinomial Logit Model için Bayesyen ve Klasik Yaklaşım: Türkiye'de Dinamik Yoksulluk Örneği ${ }^{1}$
}

\author{
Çiler SIGGEZE \\ Sorumlu Yazar, Çukurova Üniversitesi İI.I.B.F. Ekonometri Bölümü \\ csigeze@cu.edu.tr,ORCID:0000-0001-5329-5066
}

Seda ȘENGÜL

Çukurova Üniversitesi I.I.I.B.F. Ekonometri Bölümü, ORCID: 0000-0002-5648-3270

\begin{abstract}
$\ddot{\mathbf{O z}}$
Yoksulluk, herhangi bir dönem ve konumda refah düzeyindeki farklılıklara göre değişiklik gösterdiği için yoksulluğun dinamik yapısının incelenmesi oldukça önemlidir. Çalışmada TÜIKK 2009-2012 dönemi Gelir ve Yaşam Koşulları Araştırması (GYKA) panel mikro veri anketinden yararlanılarak Türkiye'de hanelerin yoksulluktan çıkış, yoksulluğa geçiş ve kronik yoksulluk durumlarının belirleyicileri rassal etkiler multinomial logit model kurularak incelenmiştir. Çalışmada rassal etkiler multinomial model hem klasik hem de Bayesyen yaklaşımla tahmin edilmiştir. Tahmin sonuçlarına göre her iki yaklaşımla benzer sonuçlar elde edilmesine rağmen Bayesyen yaklaşımla tahmin süresi klasik yaklaşıma göre on kat daha kısa sürmüştür. Bunun yanında çalışmada hanehalkı reisinin ve hanenin özelliklerinin hanenin yoksulluk geçişi ve kronik yoksul olması üzerindeki etkilerinin farklılık gösterdiği belirlenmiştir.
\end{abstract}

Anahtar Kelimeler: Kronik Yoksulluk, Geçici Yoksulluk, Rassal Etkiler Multinomial Logit Model, Bayesyen Yaklaşım.

JEL Sınıflaması: C33, C35, I30

Bayesian And Classic Approaches for Multinomial Logit Model with Random Effects: The Case of Dynamic Poverty in Turkey ${ }^{2}$

\begin{abstract}
It is important to examine the dynamic structure of poverty, as poverty can vary according to differences both in the welfare level and situation at a point in time. This study investigates the determinants of poverty outflow, transient poverty and chronic poverty in Turkey using Turkish Statistical Institute, Income and Living Conditions Survey (SILC) panel micro data by applying the multinomial logit model with random effects. In the study, the multinomial logit model with random effects were estimated both utilizing Bayesian and classic approaches. According to the results, although similar results were obtained with both approaches, the estimation period of Bayesian approach was ten times shorter than the classical approach. The results show that the feautures of the household's head and household have a different impact both on the transitory poverty and chronic poverty of household.
\end{abstract}

Keywords: Chronic Poverty, Transient Poverty, Multinomial Logit Model with Random Effects, Bayesian Approach.

JEL Classifications : C33, C35, I30

$1 \mathrm{Bu}$ çalışma Çiler SİGEZE'nin “Türkiye'de Dinamik Yoksulluğun Rassal Etkiler Multinomial Logit Model ile İncelenmesi” başlıklı doktora tezinden (Çukurova Üniversitesi, Sosyal Bilimler Enstitüsü, 2018) türetilmiştir.

2 Extended abstract is presented at the end of the article

Geliş Tarihi (Received): 03.10.2018 - Kabul Tarihi (Accepted): 29.05.2019

Atıfta bulunmak için/Cite this paper:

Sizege, Ç. ve Şengül, S. (2019). Rassal etkiler multinomial logit model için bayesyen ve klasik yaklaşım: Türkiye'de dinamik yoksulluk örneği. Çankırı Karatekin Üniversitesi İIBF Dergisi. 9 (1), 51-71. 


\section{Giriş}

Yoksulluk çalışmalarında zamanın bir noktasında elde edilen bilgiler doğrultusunda yalnızca yoksulluğun statik yapısı ele alınabilmektedir. Bu şekilde yoksulların zaman içinde yoksulluk durumlarındaki değişiklikleri incelemek ve farklı zaman ve konumdaki bireylerin yoksulluk durumlarını karşılaştırmak mümkün olmamaktadır. Ancak aynı bireylerin tekrarlı gözlemlerinin elde edildiği panel verinin toplanması ve bireylerin gelir durumları hakkında sürekli bilginin sağlanması ile yoksulluğun dinamik yapısı da incelenebilmektir. Bu bilgiler doğrultusunda yoksulluk literatüründe yer alan kronik yoksulluk ve geçici yoksulluk kavramlarının ilgilenilen bölge için ölçümlerinin yapılması ve bu yoksulluk türlerine etki eden etmenlerin ekonometrik analizler ile incelenmesi de mümkün olmuştur (Bane, Ellwood, 1986; Ravallion, 1988; Ravallion vd., 1995; McCulloch, Baulch, 1999; Hasegawa, Ueda, 2007, Kızılgöl, 2009, Limanl1, 2015).

Yoksulların kronik ve geçici yoksul olarak ayrılması konusunda ilk çalışma Bane ve Ellwood (1986)'un dönem (spells) yaklaşımı olmaktadır. Bu yaklaşıma göre analiz edilen sürenin yarısı ya da daha fazla sürede geliri yoksulluk doğrusunun altında kalan haneler kronik yoksul, analiz edilen sürenin yarısından daha az sürede geliri yoksulluk doğrusunun altında kalan haneler ise geçici yoksul haneler olarak tanımlanmaktadır. Geliri ilgilenilen dönem boyunca yoksulluk sinırının altına düşmeyen haneler ise yoksul olmayan haneler olarak sınıflandırılmaktadır (Yaqub, 2000; Israeli ve Weber, 2014).

Yoksulluk kavramının dinamik yapısının dikkate alınması ile kronik ve geçici yoksulluk olarak ayrılmasından bir sonraki aşama yoksulluk geçişlerinin incelenmesi olmuştur. Kronik yoksulluk raporuna (The Chronic Poverty Report, 2005) göre geçici yoksullar, bazı dönemlerde yoksul olup bazı dönemlerde yoksul olmayanlar olarak ifade edilmektedir. Ortalama yoksulluk skoru yoksulluk çizgisine çok yakın olan dalgalanan yoksullar ve ortalama yoksulluk skoru, yoksulluk çizgisinin üzerinde olmasına rağmen en az bir dönemde yoksul olanlar ise ara sıra yoksullar olarak tanımlanmaktadır. $\mathrm{Bu}$ tanıma göre hanelerin/bireylerin yoksulluktan çıkma ve yoksulluk durumuna geçme nedenlerinin incelenmesi ve elde edilen sonuçlara göre daha etkin yoksullukla mücadele politikalarının belirlenmesi amacıyla yoksulluk çalışmaları bu alanda yoğunlaşmaya başlamıştır.

Yoksulluk literatürüne bakıldığında hanelerin yoksul değil, geçici yoksul ve kronik yoksul şeklinde üç kategoriye ayrılması ile ekonometrik analizlerin sağlanması için üç ya da daha fazla kategoriden oluşan nitel bağımlı değişkenli modeller içerisinden multinomial logit ve sıralı logit modellerden yararlanıldığ görülmektedir. McCulloch ve Baulch (1999), Pakistan hanehalkları için dinamik yoksulluğun belirleyicilerini multinomial ve sıralı logit modeli ile incelemişlerdir. Alisjahbana ve Yusuf (2003), Endonezya'nın kırsal ve ketsel alanları için 1993 ve 
1997 dönemini baz aldığ çalışmasında hanelerin yoksul olmama, geçici yoksul olma ve kronik yoksul olma durumlarını etkileyen etmenleri multinominal logit model ile analiz etmişlerdir. Dartanto ve Nurkholis (2013), 2005-2007 y1lı için Endonezya'da yoksulluk dinamiklerinin belirleyicilerini, haneleri yoksul, yoksulluğa giren, yoksulluktan çıkan ve yoksul olmayan şeklinde sınıflandırarak, sıralı logit model yaklaşımı ile incelemişlerdir. Panel veri kullanılmasına rağmen panel veri ekonometrisinden yararlanılmayan bu çalışmalardan farklı olarak Walelign, Charlery, Smith-Hall, Chhetri ve Larsen (2016), 2006-2009, 2009-2012 yılları şeklinde iki yıllık geçiş dönemlerini kullanarak, yoksul olmayan, yoksulluğa giren ve yoksulluktan çıkan ve sürekli yoksul olarak haneleri sinıflandırarak yoksulluğun belirleyicilerini rassal etkiler logit ve rassal etkiler sıralı logit yaklaşımları ile araştırmışlardır.

Türkiye'de yoksulluğun dinamik yapısını inceleyen Kızılgöl (2009)'ün çalışması 2002-2006 yılları Hanehalkı Bütçe Anketi (HBA) verileri ile birleştirilmiş panel veri kullanarak Türkiye'de kronik ve geçici yoksulluk oranlarını hesaplayan ilk çalışma olmaktadır. Çağlayan, Koşan ve Astar (2012) ise 2009 yılı HBA verisinden yararlanarak yoksulluğu, aşırı yoksul, kronik yoksul, yoksul, yoksulluğa eğilimli, yoksul olmamaya geçiş, yoksul olmayan olarak 6 kategoriye ayırarak sıralı ve genelleştirilmiş sıralı logistik regresyon modelleri ile bu yoksulluk türlerinin belirleyicilerini incelenmişlerdir. Bunun yanında TÜİK tarafından 2006 yılında Gelir ve Yaşam Koşulları Araştırması (GYKA) panel mikro veri setinin yayınlaması ile yoksulluğun dinamik yapısının, yoksulluğa giriş-çıkışın ve sürekli yoksulluğun belirleyicilerini araştıran çalışmalarda artış görülmüştür. Şeker (2011), 2006-2007 yılları, Şeker ve Dayığlu (2014), 20052008 yılları ve Gürsel ve Acar (2015), 2008-2011 yılları için hanelerin yoksulluğa giriş ve yoksulluktan çıkışlarının belirleyicilerini incelemişlerdir. Benzer şekilde Acar ve Başlevent (2014), 2007-2008, 2008-2009 ve 2009-2010 yılları için hanehalklarının yoksulluğa giriş-çıkış nedenlerini ikili seçim modelleri ile araştırmışlardır. Dalgıç, İyidoğan ve Güven (2015), 2005-2011 yılları için hanelerin yoksulluğa girmesinde ve yoksulluktan çıkmasında ilgili faktörlerin etkisini probit model ile incelemişlerdir. Panel veri ekonometrisinden yararlanan Limanlı (2015) ise 2006-2009 yılları için yoksulluğun belirleyicilerini havuzlanmış probit, panel probit, dinamik panel probit ve Stewart model tahminleri ile elde etmiştir.

Türkiye'de yoksulluk literatüründe, hem panel verinin kullanıldığı hem de bağımlı değişkeni üç ya da daha fazla kategoriden oluşan nitel bağımlı değişkenli modeller ile dinamik yoksulluğu inceleyen çalışmalara rastlanılmamıştır. Bu çalışmada ise literatürdeki bu eksiklik göz önüne alınarak 2009-2012 dönemine ait TÜİK Gelir ve Yaşam Koşulları Araştırması (GYKA) panel mikro veri setinden yararlanarak Türkiye'de hanelerin dinamik yoksulluğu panel veriyi dikkate alan multinomial logit model ile incelenecektir. 
Panel veri zamanın farklı noktalarında aynı bireyin belli bir konu üzerindeki tekrarlı gözlemlerinden oluştuğu için bu birim etkilerin korelasyonlu olması beklenilmektedir. Panel veri modellerinin doğru istatistiksel analizi bu korelasyonun modellenmesini gerektirmektedir (Pettitt, Haynes, Tran ve Hay, 2002; Haynes, Western, Yu ve Spellak, 2008; Greene, 2003, s. 284; Johnston ve Dinardo, 1997, s. 390). Genelleştirilmiş doğrusal modellerde tekrarlı gözlemler arasındaki korelasyonu dikkate almak amacıyla modele rassal etkiler dâhil edilmektedir. $\mathrm{Bu}$ şekilde rassal etkilerin yer aldığı bağımlı değişkeni nitel modellere genelleştirilmiş doğrusal karma modeller (Genealized linear mixed models, GLMM) denilmektedir (McCulloch ve Searle, 2001; Liu, 2015, s. 247). GLMM'lerde model tahmini için rassal etkilere koşullu olan bağımlı değişkenin marjinal dağılımının tahmin edilmesi gerekmektedir. $\mathrm{Bu}$ şekilde model parametrelerinin en çok olabilirlik (maximum likelihood, ML) tahminlerini sağlamak için rassal etkilere göre olabilirlik fonksiyonunun integralinin alınması gerekmektedir. $\mathrm{Bu}$ amaçla sayısal yaklaştırma yöntemlerinden (numerical integration); MQL(marginal quasi-likelihood), PQL(penalized quasi-likelihood), GQ (Gaussian quadrature), Uyarlamalı (Gaussian) Kuadratik (Adaptive Gaussian quadrature, AGQ), Bayesyen Uyarlamalı Kuadratik, Uyarlamalı Gauss-Hermite Kuadratik, Gauss-Hermite Kuadratik gibi yaklaştırma yöntemlerinden yararlanılmaktadır (Hartzel, Agresti ve Caffo, 2001; Haan ve Uhlendorff, 2006).

GLMM sinıfında yer alan rassal etkiler MNL modelde alternatiflerin sayısının artmasıyla birlikte alternatifler arasındaki rassal birim etkinin de artması, rassal etkilere koşullu olarak bağımlı değişkenin marjinal olabilirliklerin hesaplanmasında kullanılan integral sayısının artmasına yol açmaktadır. $\mathrm{Bu}$ nedenle rassal etkiler MNL model tahminini içeren çalışmalar genel olarak farklı paket programları kullanılarak hangi yöntemin mevcut veri için daha uygun olduğu konusunu üzerine yoğunlaşmışlardır. Bu çalışmalar arasından RabeHesketh, Skrondal ve Pickles (2002), ikili ve çok değişkenli GLMM'i klasik kuadratik, uyarlamalı kuadratik ve MCMC yöntemleri ile tahmin etmişlerdir. Elde edilen sonuçlara göre uyarlamalı kuadratik ile diğer kuadratik ve MCMC yöntemlerinden hesaplama olarak daha etkin sonuçlar elde edilmiştir.

Haan ve Uhlendorff (2006) rassal etkiler MNL model tahmini için Halton dizisine dayanan simülasyon yöntemi MSL(maksimum simulated likelihood), GaussHermite kuadratik ve uyarlamalı kuadratik yaklaşımlarını karşılaştırmışlardır. Gauss-Hermite kuadratik ve uyarlamalı kuadratik yaklaşımları için STATA programında gllamm komutundan yararlanmışlardır. Sonuç olarak üç yöntem ile aynı tahminlerin elde edilmesine rağmen alternatifler arasında gözlemlenemeyen heterojenliğin varlığ edildiği vurgulanmıştır. Bunun yanında MSL'ye göre uyarlamalı kuadratik yaklaşımı ile daha güçlü sonuçlar elde edilmiştir. Sonuç olarak GLMM'in tahmini de uyarlamalı kuadratik yaklaşımla daha tutarlı sonuçlar sağlarken MSL 
ve Gauss-Hermite yaklaşımına göre hesaplama için daha fazla zaman gerektirmektedir.

Pettitt vd. (2006) panel verilerde sıklıkla karşılaşılan bazı değişkenlerin gözlenememesi (missing value) problemine çözüm olarak dinamik rassal etkiler MNL model tahmini için hiyerarşik Bayesyen yöntemi kullanmışlardır. MCMC algoritmaları için Gibbs örneklemesi kullandıklarını çalışmalarında WINBUGS programından yararlanmışlardır.

Haynes vd. (2008) ise rassal etkiler MNL modeli hem Bayesyen hem de klasik yaklaşım ile tahmin etmişlerdir. Bayesyen yaklaşım olarak Gibbs örneklemesi ile MCMC simülasyonunu WINBUGS programında, klasik yaklaşım olarak ise STATA'da gllamm komutu ile uyarlamalı kuadratik yaklaştırma yöntemini kullanmışlardır. Elde edilen sonuçlara göre MCMC simülasyon yönteminin tahminlerde daha esnek olduğundan ve uyarlamalı kuadratik yaklaşıma göre daha az hesaplama yoğunluğu gerektirdiğinden bahsetmişlerdir.

Klasik kuadratik yöntemlere göre simülasyon yöntemlerinin daha avantajlı olduğunu vurgulayan bir çalışma da Hadfield (2010) tarafindan gerçekleştirilmiştir. Hadfield (2010), MCMC tekniği içerisinden MetropolishHastings algoritması kullanılarak GLMM'i tahmin etmek için, kısıtsız kovaryans matrislerine ve çeşitli hata ve rassal etki varyans yapılarına izin vererek oldukça etkin bir yöntem sunmaktadır. $\mathrm{Bu}$ yöntemin en büyük avantaj1 büyük örneklemlerle çalışıldığı durumda bile analizin gerçekleşmesi için gerekli zamanın klasik tahmin yöntemlerine göre daha kısa olmasıdır.

Literatürde yer alan çalışmalara bakıldığında MCMC simülasyon yöntemlerine dayanan Bayesyen yaklaşım ve uyarlamalı kuadratik yaklaşım ile en çok olabilirlik (ML) tahmini rassal etkiler MNL model tahmini için sıklıkla tercih edilen ve önerilen yöntemler olmaktadır.

$\mathrm{Bu}$ bilgiler doğrultusunda bu çalışmada hanelerin dinamik yoksulluğunun belirleyicileri rassal etkiler multinomial logit model (MNL) ile incelenecektir. Bunun yanında rassal etkiler MNL modelin hem klasik hem de Bayesyen tahmini yapilacaktır.

\section{Materyal ve Yöntem}

Çalışmada TÜİK tarafından derlenen 2009-2012 dönemine ait Gelir ve Yaşam Koşulları Araştırması (GYKA) veri setinden yararlanılmıştır. GYKA'da 2009 yılındaki 2975 hanehalkı devam eden üç yıl boyunca takip edilerek panel veri seti oluşturulmuştur. $\mathrm{Bu}$ sürede bazı hanehalkları, adrese ulaşılamama, ülke sınırları dışına taşınma, iki yıl üst üste cevapsızlık ve ölüm gibi nedenlerle örneklemden çıkarılmıştır. Son olarak panel veri seti için hanehalkı sayısı 2732 ve dört yıllık dengeli panel veri seti için örneklem boyutu 10928 olmuştur. 
Çalışmada yer alan haneleri "yoksul" ve "yoksul değil" şeklinde sınıflandırmak amacıyla, öncelikle TÜIKK tarafından kullanılan OECD eşdeğerlik ölçeği kullanılarak eşdeğer hanehalkı büyüklükleri hesaplanmıştır. Hanelerin hanehalkı toplam yıllık geliri, eşdeğer hanehalkı büyüklüğüne bölünerek o hanehalkı için eşdeğer fert başına düssen gelir hesaplanmıştır. Ardından TÜiK(2016) tarafindan hesaplanan 2009-2012 yıllarına ait eşdeğer fert başına düşen medyan gelirin \%60'1 olarak belirlenen yoksulluk sinırları sirasıyla 4227, 4457, 4883 ve 5418 TL olarak alınarak, yoksulluk sınırının altında gelire sahip olan haneler yoksul, sınırın üstünde gelire sahip olan haneler ise yoksul değil şeklinde sınıflandırılmıştır. Ardından yoksullar arasındaki farklılığı da dikkate almak için yoksullar, yoksulluğa giren ve yoksulluktan çıkan ve kronik yoksul olarak ayrılmaktadır. Çalışmada geçici yoksul olarak da sınıflandırılan yoksulluğa giren ve yoksulluktan çıkan haneleri ve kronik yoksul olan haneleri belirlemek amacıyla Bane ve Ellwood (1986)'un dönem yaklaşımından yararlanılmaktadır. Bu yaklaşıma göre analiz edilen sürenin yarısı ya da daha fazla sürede geliri yoksulluk sınırının altında kalan haneler kronik yoksul, analiz edilen sürenin yarısından daha az sürede geliri yoksulluk sınırının altında kalan haneler ise geçici yoksul haneler olarak tanımlanmaktadır. Geçici yoksul hanelerde kendi içerisinde, bir önceki dönemde yoksul iken daha sonraki dönemde yoksul değil ise "yoksulluktan çıkan", bir önceki dönemde yoksul değil ancak bir sonraki dönemde yoksul ise "yoksulluğa giren" olarak tanımlanmaktadır. Hane her iki dönemde de yoksul değil ise "yoksul olmayan" olarak tanımlanırken üst üste ya da daha sonraki dönemde de yoksul ise analiz edilen sürenin yarısında yoksul olduğu için "kronik yoksul" olarak değerlendirilmektedir.

Çalışmada hanelerin yoksul olmama, yoksulluğa girme, yoksulluktan çıkma ve kronik yoksul olma durumlarının belirleyicilerini araştırmak amacıyla kullanılan açıklayıcı değiş̧kenler ve tanımları Tablo 1'de sunulmuştur. Değişkenler, ilgili literatür takip edilerek oluşturulmuştur. 
Tablo 1: Açıklayıcı Değişkenler ve Tanımları

\begin{tabular}{|c|c|}
\hline Değişkenler & Tanımlar \\
\hline \multicolumn{2}{|c|}{ Hanehalkı Reisinin Özellikleri } \\
\hline Cinsiyet & Hanehalkı reisi kadın ise 1 , değil ise 0 \\
\hline Yaş & Hanehalkı reisinin yaşı \\
\hline Yaşın karesi & Hanehalkı reisinin yaşının karesi \\
\hline Evli & Hanehalk1 reisi evli ise 1 , diğer durumda 0 \\
\hline $\begin{array}{l}\text { Kronik hastalık } \\
\text { SGK }\end{array}$ & $\begin{array}{l}\text { Hanehalkı reisi kronik hasta ise } 1 \text {, değil ise } 0 \\
\text { Hanehalk1 reisi SGK'ya kayıtll ise } 1 \text {, değil ise } 0\end{array}$ \\
\hline İş değiştirme & $\begin{array}{l}\text { Hanehalk1 reisinin son bir ylda iş değiştirdiği } \\
\text { durumda } 1 \text {, diğer durumda } 0\end{array}$ \\
\hline \multicolumn{2}{|c|}{ Hanehalkı Reisinin Eğitim Durumu } \\
\hline $\begin{array}{l}\text { Okur-yazar değil } \\
\text { (Referans) }\end{array}$ & $\begin{array}{l}\text { Hanehalkı reisi okur-yazar değil, okur-yazar olup bir } \\
\text { okul bitirmedi ise } 1 \text {, diğer durumda } 0\end{array}$ \\
\hline İlköğretim & $\begin{array}{l}\text { Hanehalk1 reisi ilkokul, ortaokul, mesleki ortaokul } \\
\text { ve ilköğretim mezunu ise } 1 \text {, değil ise } 0\end{array}$ \\
\hline Lise & $\begin{array}{l}\text { Hanehalk1 reisi genel lise, mesleki veya teknik lise } \\
\text { mezunu ise } 1 \text {, değil ise } 0\end{array}$ \\
\hline Yüksekokul & $\begin{array}{l}\text { Hanehalkı reisi yüksekokul, fakülte ve üzeri mezunu } \\
\text { ise } 1 \text {, değil ise } 0\end{array}$ \\
\hline \multicolumn{2}{|c|}{ Hanehalkı Reisinin İş Durumu } \\
\hline Ücretli, maaşlı & $\begin{array}{l}\text { Hanehalkı reisi ücretli, maaşlı çalışıyor ise } 1 \text {, değil } \\
\text { ise } 0\end{array}$ \\
\hline Kendi hesabina & $\begin{array}{l}\text { Hanehalk1 reisi kendi hesabına çalışyyor ise } 1 \text {, değil } \\
\text { ise } 0\end{array}$ \\
\hline Emekli & Hanehalkı reisi emekli ise 1 , değil ise 0 \\
\hline Aktif değil & $\begin{array}{l}\text { Hanehalk1 reisi yaşlı, engelli veya çalışamaz halde } \\
\text { ise } 1 \text {, değil ise } 0\end{array}$ \\
\hline \multicolumn{2}{|l|}{ Hanenin Özellikleri } \\
\hline Gelir & Hanenin eşdeğer hanehalkı kullanabilir fert geliri \\
\hline Logaritmik gelir & $\begin{array}{l}\text { Hanenin eşdeğer hanehalkı kullanabilir fert gelirinin } \\
\text { logaritması }\end{array}$ \\
\hline Ev sahipliği & Ev sahibi ise 1 , değil ise 0 \\
\hline \multicolumn{2}{|l|}{ Hanehalkı Tipi } \\
\hline Tek kişilik(Referans) & Tek kişilik hanehalkı ise 1 , diğer durumda 0 \\
\hline Bağımlı çocuk yok & Bağımlı çocuk olmayan hanehalkı ise 1 , değil ise 0 \\
\hline Bağımlı çocuk & Bağımlı çocuk olan hanehalkı ise 1 , değil ise 0 \\
\hline
\end{tabular}


Çalışmada McFadden(1973) tarafindan geliştirilen genel multinomial logit model (MNL), hanelerin tekrarlı gözlemleri arasındaki korelasyonu dikkate almak amacıyla rassal birim etkili MNL model olarak ele alınmaktadır. Bağımlı değişken hanelerin bir dönem önceki yoksulluk durumlarına göre yoksul olmayan (1), yoksulluktan çıkan (2), yoksulluğa giren (3) ve kronik yoksul (4) şeklinde dört kategoriden oluşmaktadır. Buna göre rassal etkiler MNL model, $X_{i t}$ özelliklerine sahip i-nci hanenin $t$ zamanında $j$ yoksulluk durumunda bulunmasının olasılığ $P\left(Y_{i t}=j / X_{i t}\right)$ olmak üzere Eşitlik (1)'de verilmektedir (Haan ve Uhlendorff, 2006; Haynes vd.,2008).

$$
\pi_{i t j}=P\left(Y_{i t}=j / X_{i t}, \alpha_{i}\right)=\frac{\exp \left(X_{i t} \beta_{j}+\alpha_{i j}\right)}{\sum_{k=1}^{j} \exp \left(X_{i t} \beta_{j}+\alpha_{i k}\right)} j=1,2,3,4 ; t=2010,2011,2012
$$

Multinomial logit modelin tahmini için yoksul olmayan (1) referans kategori olarak ele alınmıştır. Rassal etkiler multinomial logit model tahmini en çok olabilirlik yaklaşımıyla yapılmaktadır. Olabilirlik fonksiyonu Eşitlik (2) şeklinde yazilmaktadır.

$$
L=\prod_{i=1}^{N} \int_{-\infty}^{+\infty} \prod_{t=1}^{T_{i}} \prod_{j=1}^{J}\left(\frac{\exp \left(X_{i t} \beta_{j}+\alpha_{i j}\right)}{\sum_{k=1}^{j} \exp \left(X_{i t} \beta_{j}+\alpha_{i k}\right)}\right)^{d_{i j t}} f\left(\alpha_{i}\right) d \alpha_{i}
$$

i-nci birey $\mathrm{t}$ zamanında $\mathrm{j}$ yoksulluk durumunda bulunursa $d_{i j t}$, bir değerini almaktadır aksi durumda sıfır değerini almaktadır (Haan ve Uhlendorff, 2006). Gözlemlenemeyen birim etki $\alpha_{i}$ 'nin sıfır ortalama ve $\Sigma$ varyans-kovaryans matrisi ile çok değişkenli normal dağıldığı varsayılmaktadır. Rassal etkiler multinomial logit modelin olabilirlik fonksiyonunun maksimizasyonu için gözlemlenemeyen birim etkinin dağılımına göre integralin çözümü gerekmektedir (Haynes, vd., 2008).

Bu çalışmada rassal etkiler multinomial logit modelin tahmini için hem klasik hem de Bayesyen yöntemden yararlanılmıştır. Klasik analiz için STATA programında genelleştirilmiş doğrusal karma modelleri, yapısal eşitlik modelleri (SEM) ve gizli değişkenler için yapısal model ve tepki modelleri birleştiren ve genelleştirilmiş doğrusal gizli ve karma modeller (Generalized Linear Latent and Mixed Models, GLLAMM) olarak bilinen modellerin tahmini için geliştirilen gllamm paketinden yararlanılmaktadır. gllamm paketinde örneklem olabilirliğini maksimize etmek için gözlenemeyen rassal etkilerin dağılımı üzerinden 
integrallerin hesaplanabilmesi amacıyla uyarlamalı kuadratik yaklaşım kullanılmaktadır (Rabe-Hesketh vd., 2002; Haan ve Uhlendorff, 2006).

Rassal etkiler MNL modelin Bayesyen tahmini için $\mathrm{R}$ paket programında Hadfield (2010) tarafından MCMC tekniği kullanılarak GLMM'leri tahmin etmek için geliştirilen $M C M C g l m m$ isimli paketten yararlanılmıştır.

\section{Araştırma Bulguları}

\subsection{Rassal Etkiler Multinomial Logit Modelin Klasik Tahmini}

Türkiye'de hanelerin yoksulluktan çıkış, yoksulluğa geçiş ve kronik yoksul olma durumlarının belirleyicilerini incelemek amacıyla oluşturulan rassal etkiler MNL model en çok olabilirlik yöntemi ile tahmin edilmiştir. En çok olabilirlik yönteminde integral yaklaştırmalarının kesinliği ve geçen zaman kuadratik noktaların sayısına göre değiştiği için analiz 4,8 ve 12 kuadratik nokta ile tekrarlanmıştır. $\mathrm{Bu}$ üç kuadratik nokta ile tahmin edilen katsayıların standart hataları ve logaritmik olabilirlik değerleri birbirlerine çok yakın olduğu için 4 kuadratik nokta yeterli bulunmuştur. Buna göre STATA programında 4 kuadratik nokta ile yaklaşı olarak 120 saat sonunda elde edilen rassal etkiler MNL model tahmin sonuçları Tablo 2'de yer almaktadır.

Tablo 2 incelendiğinde, rassal etkiler MNL modelinde kullanılan değişkenlerin parametre tahminlerinin çoğu istatistiksel olarak anlamlı bulunmuştur. Yoksulluktan çıkan, yoksulluğa giren ve kronik yoksul hanelerin rassal birim etkilerinin varyansları sırasıyla $0.061,0.398$ ve 0.301 elde edilmiştir. Bu bulgu modelde hanelerin kendilerine özgü gözlenemeyen bir heterojenliğinin olduğunu göstermektedir. Heterojenliğin derecesi yoksulluktan çıkan haneler için diğer hanelere göre daha düşüktür. Rassal etkilerin korelasyonlarına bakıldığında ise yoksulluktan çıkan ve yoksulluğa giren hanelerin gözlenemeyen özelliklerini içeren rassal birim etkiler arasında 0.448 değerinde pozitif ilişki bulunmuştur. $\mathrm{Bu}$ değere göre ilgili yıllarda yoksulluğa giren ve yoksulluktan çıkan hanelerin benzer bir gözlenemeyen etkiyi paylaştıkları söylenebilmektedir. Yoksulluktan çıkan ve kronik yoksul hanelerin rassal etkileri arasındaki korelasyon yine pozitif olmakla birlikte bu etkinin diğer korelasyon değerlerine göre daha düşük olması beklenilen bir sonuçtur. Aynı zamanda yoksulluğa giren ve kronik yoksul hanelerin rassal birim etkileri arasında 0.966 değerinde güçlü bir pozitif ilişki bulunmuştur. $\mathrm{Bu}$ bulgu da hanelerin yoksulluğa düşmelerinde ve kronik yoksul olmalarında hanelerin gözlenemeyen özelliklerinin ortak bir etkisi olduğunu göstermektedir. 
Tablo 2: Rassal Etkiler MNL Modelin Klasik Tahmin Sonuçları

\begin{tabular}{|c|c|c|c|}
\hline Değişkenler & Yoksulluktan Çıkan & Yoksulluğa Giren & Kronik Yoksul \\
\hline \multirow{2}{*}{ Cinsiyet } & $-0.654^{*}$ & $-0.765^{*}$ & $-1.313^{*}$ \\
\hline & $(0.227)$ & $(0.266)$ & $(0.226)$ \\
\hline \multirow{2}{*}{ Yaş } & 0.056 ** & $0.202 *$ & $0.230^{*}$ \\
\hline & $(0.025)$ & $(0.029)$ & $(0.025)$ \\
\hline \multirow{2}{*}{ Yaşın karesi } & $-0.0006^{* *}$ & $-0.001 *$ & $-0.002 *$ \\
\hline & $(0.0002)$ & $(0.0002)$ & $(0.0002)$ \\
\hline \multirow{2}{*}{ Evli } & -0.103 & 0.190 & $0.412 * * *$ \\
\hline & $(0.232)$ & $(0.277)$ & $(0.238)$ \\
\hline \multirow{2}{*}{ Kronik hastalık } & $0.208 * * *$ & 0.145 & $0.210 * * *$ \\
\hline & $(0.117)$ & $(0.135)$ & $(0.117)$ \\
\hline \multirow{2}{*}{ SGK } & $-0.380 * *$ & -0.151 & $-0.909^{*}$ \\
\hline & $(0.147)$ & $(0.177)$ & $(0.154)$ \\
\hline \multirow{2}{*}{ İş değiştirme } & $0.597^{*}$ & 0.218 & 0.031 \\
\hline & $(0.166)$ & $(0.202)$ & $(0.177)$ \\
\hline \multirow{2}{*}{ İlköğretim } & $-0.781^{*}$ & $-0.589^{*}$ & $-1.190^{*}$ \\
\hline & $(0.153)$ & $(0.177)$ & $(0.151)$ \\
\hline \multirow{2}{*}{ Lise } & $-1.729^{*}$ & $-1.052 *$ & $-2.047^{*}$ \\
\hline & $(0.233)$ & $(0.257)$ & $(0.230)$ \\
\hline \multirow{2}{*}{ Yüksekokul } & $-2.541^{*}$ & $-0.945 * * *$ & $-1.818^{*}$ \\
\hline & $(0.483)$ & $(0.540)$ & $(0.522)$ \\
\hline \multirow{2}{*}{ Ücretli, maaşlı } & -0.292 & $-0.362 * * *$ & $-0.436 * *$ \\
\hline & $(0.180)$ & $(0.213)$ & $(0.178)$ \\
\hline \multirow{2}{*}{ Kendi hesabına } & $0.567^{*}$ & $0.470 * *$ & 0.124 \\
\hline & $(0.151)$ & $(0.181)$ & $(0.153)$ \\
\hline \multirow{2}{*}{ Emekli } & $-0.931^{*}$ & -0.289 & $-1.443^{*}$ \\
\hline & $(0.231)$ & $(0.249)$ & $(0.236)$ \\
\hline \multirow{2}{*}{ Aktif değil } & $0.484 * *$ & $0.657 * *$ & $0.870^{*}$ \\
\hline & $(0.233)$ & $(0.267)$ & $(0.225)$ \\
\hline \multirow{2}{*}{ Gelirin logaritmas 1} & $-1.758^{*}$ & $-6.250 *$ & $-6.937 *$ \\
\hline & $(0.140)$ & $(0.209)$ & $(0.198)$ \\
\hline \multirow{2}{*}{ Ev sahipliği } & -0.003 & $0.370^{*}$ & $0.530 *$ \\
\hline & $(0.115)$ & $(0.134)$ & $(0.117)$ \\
\hline \multirow{2}{*}{ Bağımlı çocuk yok } & $0.524 * * *$ & $2.329 *$ & $2.354 *$ \\
\hline & $(0.273)$ & $(0.320)$ & $(0.288)$ \\
\hline \multirow{2}{*}{ Bağımlı çocuk olan } & $2.037 *$ & $5.106^{*}$ & $6.103^{*}$ \\
\hline & $(0.280)$ & $(0.348)$ & $(0.315)$ \\
\hline \multirow{2}{*}{ Sabit } & $13.209^{*}$ & $48.189 *$ & $54.742 *$ \\
\hline & (1.299) & $(1.827)$ & $(1.700)$ \\
\hline \multirow[t]{2}{*}{ Birim Varyans } & 0.061 & 0.398 & 0.301 \\
\hline & $(0.065)$ & $(0.207)$ & $(0.234)$ \\
\hline
\end{tabular}

Not: Parantez içindeki değerler katsayıların standart hatalarıdır. ***,**,*, sırasıyla \%10, $\% 5$ ve \%1 önem düzeylerini göstermektedir. 
Tablo 2'de anlamlı katsayılar arasında hanelerin yoksul olmamasına göre hanelerin yoksulluğa girmesini ve yoksulluktan çıkmasını etkileyen değişkenlerin katsayı büyüklükleri farklı, ancak katsayıların aynı işarete sahip olduğu gözlenmiştir. $\mathrm{Bu}$ bulgu ve yoksulluğa giren ve yoksulluktan çıkan hanelerin benzer bir gözlenemeyen rassal etkiyi paylaşmaları nedeniyle çalışmada yoksulluğa giren ve yoksulluktan çıkan haneler genel olarak geçici yoksul haneler olarak sınıflandırılmıştır.

Tablo 2'ye göre hanehalkı reisinin yaşı, yoksul olmayanlara göre hem geçici yoksulluk hem de kronik yoksulluk üzerinde pozitif, hanehalkı reisinin yaşının karesi ise negatif bir etkiye sahiptir. Bu bulgu, hanehalkı reisinin yaşı arttıkça hanelerin hem geçici hem de kronik yoksul olma olasılıklarının arttığını ancak belli bir yaştan sonra ise yaş artışı ile birlikte hanelerin yoksul olma olasılıklarının azalacağını göstermektedir.

Çalışmada, hanehalkı reisi kadın olan hanelerin geçici yoksul ve kronik yoksul olma olasılıklarının hanehalkı reisi erkek olanlara göre daha az olduğu sonucu elde edilmiştir. Bunun yanında hanehalkı reisinin kadın olduğu hanelerde kronik yoksul olma olasılığı hanenin geçici yoksul olma olasılığından daha düşüktür. $\mathrm{Bu}$ bulgu, hanehalkı reisinin kadın olmasının yoksulluğu arttıran bir etkiye sahip olduğu yönündeki genel kanıya ters olmakla birlikte yoksulluk çalışmalarıyla ilgili literatür de bu sonucu desteklemektedir. Öyle ki Devicienti (2002) ve Andriopoulou ve Tsakloglou (2011) çalışmalarında hanehalkı reisi kadın olanların yoksulluktan çıkmak için bir yol bulabileceğini ancak bu hanelerin yoksulluğa geçmesi üzerinde cinsiyetin herhangi bir etkisinin olmadığını söylemişlerdir. Wallelign vd. (2016) de hanedeki yetişkin kadın sayısındaki artışın hanenin yoksulluktan çıkma, yoksulluğa girme ve kronik yoksul olma riskini düşürdüğünü ancak hanehalkı reisinin cinsiyetinin yoksulluk durumu üzerinde herhangi bir etkisi olmadığını bulmuşlardır. Acar ve Başlevent (2014), hanehalkı reisi erkek olanlara göre hanehalkı reisi kadın olanların yoksulluktan çıkma olasılıklarının daha fazla olduğunu, yoksulluğa girme olasılıklarının ise daha az olduğunu belirtmişlerdir. Benzer şekilde Dalgıç vd. (2015) çalışmalarında, hanehalkı reisinin kadın olmasının yoksulluk riskini azalttığından bahsetmişlerdir.

Tablo 2'ye göre hanehalkı reisinin evli olmasının hanenin yoksul olmamasına göre hanenin geçici yoksul olmasında bir etkisi bulunmazken hanenin kronik yoksul olma olasılığı üzerinde pozitif bir etkisi bulunmuştur. Benzer şekilde Walelign vd. (2016) de hanehalkı reisinin evli olmasının, hanelerin yoksul olmamasına göre yoksulluktan çıkma, yoksulluğa girme ve kronik yoksul olma olasılıklarını pozitif olarak etkilediğini bulmuşlardır.

Tablo 2'ye göre hanehalkı reisinin eğitim seviyesi arttıkça hanelerin hem geçici yoksul hem de kronik yoksul olma olasılıklarının artan oranda azaldığı gözlenmektedir. Eğitim düzeyindeki artışın hanenin yoksulluktan çıkma olasılığını arttırması beklenirken negatif katsayılar elde edilmesinin, yoksulluktan 
çıkan hanelerin geçici yoksul kategorisinde yer alması nedeniyle olduğu düşünülmektedir. Hanehalkı reisinin okur-yazar olmadığı ya da okur-yazar olup bir okul bitirmediği hanelere göre hanehalkı reisinin genel lise, mesleki veya teknik lise mezunu olmasının ise kronik yoksul olma olasılığını önemli ölçüde düşürdüğü gözlenmiştir.

Tablo 2'de hanehalkı reisinin ücretli, maaşlı olmasının hanenin yoksul olmamasına göre hanenin yoksulluğa girme ve kronik yoksul olma olasılığını negatif etkilediği görülmektedir. Bu bulgu hanehalkı reisinin düzenli maaş almasının hanenin yoksulluk riskini azalttığını göstermektedir. Çalışmada ayrıca hanehalkı reisinin emekli olmasının hanelerin kronik yoksul olmalarını negatif etkilediği bulunmuştur. Buna göre hanehalkı reisi emekli olan hanelerin düzenli gelirleri nedeniyle kronik yoksulluk gibi yoksulluğu daha şiddetli yaşayan kesimde yer alması daha az olasidır.

Tablo 2'de hanehalkı reisinin kendi hesabına çalışmasının hanenin yoksulluktan çıkması ve yoksulluğa girme olasılığını pozitif etkilediği, hanenin kronik yoksul olma olasılığı üzerinde ise anlamlı bir etkisinin olmadığı belirlenmiştir. Bu bulgu, hanehalkı reisi kendi hesabına çalışan hanelerin ekonomik faktörler gibi negatif şoklardan etkilenen geçici yoksul haneler olduğunu bunun yanında kronik yoksul olacak kadar gelirden yoksun olmadıklarını göstermektedir. Bunun yanında hanehalkı reisi yaşlı, engelli veya çalışamaz halde olan hanelerin geçici ve kronik yoksul olma olasılıkları da pozitif bulunmuştur.

Hanehalkı reisinin Soysal Güvenlik Kurumu'na (SGK)'ya kayıtlı olmasının hanenin kronik yoksul olma olasılığını negatif etkilediği, yoksulluğa girme olasılığ üzerinde ise anlamlı bir etkisinin olmadığ 1 belirlenmiştir. Buna ek olarak hanehalkı reisinin geçen yıldan bu yana iş değişikliği yapması hanenin yoksulluktan çıkma olasılığını pozitif etkilemektedir. Hanehalkı reisinin daha yüksek gelirli bir iş nedeniyle iş değişikliği yaptığı varsayılırsa hanenin gelirini artırdığı ve bu nedenle yoksulluktan çıkma olasılığı üzerinde olumlu bir etki yaptığ 1 söylenebilir. Bunun yanında hanehalkı reisinin iş değiştirme dönemleri arasında hanelerin yoksulluğa girme olasılıklarında herhangi bir anlamlı etkinin görülmemesinde işsizlik sigortalarının ya da tasarrufların etkisinin olduğu düşünülmektedir.

Çalışmada hanehalkının ev sahibi olmasının hanenin yoksulluktan çıkma olasılığı üzerinde anlamlı bir etkisi bulunmamıştır. Bunun yanında hanehalkının ev sahipliğinin hanenin yoksulluğa girme ve kronik yoksul olma riskini arttırdığ sonucu elde edilmiştir. Buna göre Türkiye'de ev sahipliğinin hanelerin refah göstergesi olmadığı ve ayrıca yoksullar arasında ev sahipliğinin daha yüksek oranlarda olduğu görülmektedir.

Çalışmada tek kişilik hanelere göre bağımlı çocuğu olan ve bağımlı çocuğu olmayan hanelerin geçici yoksul ve kronik yoksul olma risklerinin daha fazla 
olduğu ve bağımlı çocuğu olan hanelerin bu riski daha fazla hissettiği elde edilmiştir. Benzer şekilde, Acar ve Başlevent (2014), bağımlı çocuk sayısının fazla olmasının hanelerin yoksulluktan çıkma olasılığını azalttığını, hanelerin yoksulluğa girme riskini ise arttırdığını bulmuşlardır. Buna göre gelişmiş ülkelerde olduğu gibi bağımlı çocuğu olan hanehalklarına çocuk yardımı yapılması, bu hanelerin yoksulluklarının kronikleşmesini engelleyebilecektir.

Tablo 3'e göre hanehalkı gelirinin beklenildiği gibi hanelerin geçici ve kronik yoksul olma riskini önemli bir oranda azalttığı görülmektedir. Buna göre yoksulluğun ortadan kaldırılması ve yoksulluğu azaltılması amaciyla hane gelirinin arttırılması oldukça önemlidir.

\subsection{Rassal Etkiler Multinominal Logit Modelin Bayesyen Tahmini}

Rassal etkiler MNL modelin Bayesyen tahmini için R paket programında Hadfield (2010) tarafından MCMC tekniği kullanılarak GLMM'leri tahmin etmek için geliştirilen MCMCglmm isimli paketten yararlanılmıştır. MCMC simülasyon yönteminin Metropolish-Hastings algoritmasının kullanıldığı çalışmada bağımlı değişkenlerin multinomial dağımlı olduğu varsayılmaktadır. Bunun yanında benzer modeller ile çalışan Pettitt vd. (2006), Haynes vd. (2008) takip edilerek çalışmada parametreler için bilgi içermeyen normal önsel dağılımlar, rassal birim etkiler için sıfır ortalamalı ve $(2 \times 2)$ boyutlu $\Sigma$ varyans ile çok değişkenli normal önsel dağılımlar, $\Sigma$ (ko)varyans matrisi için ise önsel dağılım olarak ters-Wishart dağılımı kullanılmıştır.

Çalışmada 250 bin iterasyonun kullanıldığ 1 algoritmada yakınsamanın gerçekleştiği iterasyon sayısı (burn-in period) 100 bin olarak belirlenmiş ve toplam iterasyon sayısından çıkarılmıştır. Böylece parametreler başlangıç değerlerinin etkisinden arındırılmıştır. Bunun yanında iki zincirin kullanıldığı algoritmada zincirler arasında olası korelasyonun etkisini yok etmek amaciyla seyreltme (thinnig) sayısı 100 olarak alınmıştır. Buna göre yalnızca her 100 iterasyon sonundaki sonuç kaydedilmekte ve böylece otokorelasyon sorunu da ortadan kaldırılmış olmaktadır.

Çalışmada MCMC yöntemindeki zincirlerin yakınsadığının test edilmesi amacıyla Gelman-Rubin (1992) yakınsama testi kullanılmaktadır. Gelman-Rubin istatistiğine göre yakınsamanın sağlanması için hesaplanan potansiyel ölçeği azaltma fonksiyonu (potential scale reduction function, Psrf) değerinin ve her bir katsayı için nokta tahminlerinin 1.1 ya da 1.2 'den küçük olması gerekmektedir. Yapılan test sonucunda Psrf değeri ve bütün katsayılar için nokta tahmini 1.2'den küçük çıkmıştır ve yakınsama sağlanmıştır. MCMC yöntemindeki zincirlerin yakınsadığından emin olunduğu durumda elde edilen katsayı tahminlerinin güvenilir olduğu söylenebilmektedir. Sonuç olarak rassal etkiler MNL modelin Bayesyen yaklaşım ile 12 saatin sonunda elde edilen parametre tahminlerinin sonsal dağılım ortalamaları ve standart hataları Tablo 3 'te sunulmuştur. 
Tablo 3: Rassal Etkiler MNL Modelin Bayesyen Tahmin Sonuçları

\begin{tabular}{|c|c|c|c|}
\hline Değişkenler & $\begin{array}{c}\text { Yoksulluktan } \\
\text { Çıkan }\end{array}$ & $\begin{array}{l}\text { Yoksulluğa } \\
\text { Giren }\end{array}$ & $\begin{array}{l}\text { Kronik } \\
\text { Yoksul }\end{array}$ \\
\hline \multirow{2}{*}{ Cinsiyet } & $-0.803^{*}$ & $-0.889 *$ & $-1.636^{*}$ \\
\hline & $(0.273)$ & $(0.311)$ & $(0.275)$ \\
\hline \multirow{2}{*}{ Yaş } & $0.063^{*}$ & $0.240^{*}$ & $0.276^{*}$ \\
\hline & $(0.028)$ & $(0.033)$ & $(0.030)$ \\
\hline \multirow{2}{*}{ Yaşın karesi } & $-0.0007 *$ & $-0.002 *$ & $-0.002 *$ \\
\hline & $(0.0002)$ & $(0.0003)$ & $(0.0002)$ \\
\hline \multirow{2}{*}{ Evli } & -0.104 & 0.249 & 0.498 \\
\hline & $(0.284)$ & $(0.327)$ & $(0.288)$ \\
\hline \multirow{2}{*}{ Kronik hastalık } & 0.262 & 0.173 & 0.254 \\
\hline & $(0.141)$ & $(0.161)$ & $(0.143)$ \\
\hline \multirow{2}{*}{ SGK } & $-0.493 *$ & -0.204 & $-1.134 *$ \\
\hline & $(0.174)$ & $(0.212)$ & $(0.187)$ \\
\hline \multirow{2}{*}{ İş değiştirme } & $0.736^{*}$ & 0.296 & 0.048 \\
\hline & $(0.203)$ & $(0.240)$ & $(0.226)$ \\
\hline \multirow{2}{*}{ İlköğretim } & $-0.971 *$ & $-0.715 *$ & $-1.456^{*}$ \\
\hline & $(0.184)$ & $(0.210)$ & $(0.186)$ \\
\hline \multirow{2}{*}{ Lise } & $-2.107 *$ & $-1.314^{*}$ & $-2.578 *$ \\
\hline & $(0.270)$ & $(0.302)$ & $(0.279)$ \\
\hline \multirow{2}{*}{ Yüksekokul } & $-3.098 *$ & $-1.197^{*}$ & $-2.110 *$ \\
\hline & $(0.578)$ & $(0.629)$ & $(0.643)$ \\
\hline \multirow{2}{*}{ Ücretli, maaşlı } & -0.368 & -0.453 & $-0.581 *$ \\
\hline & $(0.211)$ & $(0.251)$ & $(0.217)$ \\
\hline \multirow{2}{*}{ Kendi hesabına } & $0.698^{*}$ & $0.604 *$ & 0.150 \\
\hline & $(0.188)$ & $(0.215)$ & $(0.191)$ \\
\hline \multirow{2}{*}{ Emekli } & $-1.112 *$ & -0.356 & $-1.775^{*}$ \\
\hline & $(0.266)$ & $(0.292)$ & $(0.282)$ \\
\hline \multirow{2}{*}{ Aktif değil } & $0.594 *$ & $0.780^{*}$ & $1.065^{*}$ \\
\hline & $(0.281)$ & $(0.322)$ & $(0.278)$ \\
\hline \multirow{2}{*}{ Gelirin logaritması } & $-2.131 *$ & $-7.438^{*}$ & $-8.458 *$ \\
\hline & $(0.149)$ & $(0.260)$ & $(0.233)$ \\
\hline \multirow{2}{*}{ Ev sahipliği } & -0.032 & $0.412 *$ & $0.629 *$ \\
\hline & $(0.139)$ & $(0.163)$ & $(0.148)$ \\
\hline \multirow{2}{*}{ Bağımlı çocuk yok } & $0.636^{*}$ & $2.724^{*}$ & $2.842 *$ \\
\hline & $(0.319)$ & $(0.384)$ & $(0.357)$ \\
\hline \multirow{2}{*}{ Bağımlı çocuk olan } & $2.471^{*}$ & $6.014^{*}$ & $7.424 *$ \\
\hline & $(0.324)$ & (0.409) & $(0.380)$ \\
\hline \multirow{2}{*}{ Sabit } & $16.087^{*}$ & $57.435^{*}$ & $67.024 *$ \\
\hline & $(1.726)$ & $(2.587)$ & $(2.392)$ \\
\hline
\end{tabular}

Not: *, \%5 önem düzeylerini göstermektedir. 
Tablo 3'te yer alan rassal etkiler MNL modelin Bayesyen yöntemle hesaplanan katsayıları, Tablo 2'de yer alan rassal etkiler MNL modelin en çok olabilirlik yöntemiyle hesaplanan katsayılarından küçük bir farkla büyük çıkmasıyla birlikte her iki yöntemle elde edilen katsayıların anlamlılıkları ve işaretleri benzerlik göstermektedir. En çok olabilirlik ve Bayesyen yaklaşımdan elde edilen katsayılar arasında önemli bir fark olmamasının nedeni Bayesyen yaklaşımda parametrelere ilişkin önsel dağılımın bilgi içermeyen önsel dağılım olmasıdır.

Rassal etkiler MNL modelin uyarlamalı kuadratik yaklaştırma yönteminin kullanıldığı en çok olabilirlik tahminlerinin standart hatalarının, MCMC ile sağlanan Bayesyen tahminlerinin standart hatalarından daha küçük olması en çok olabilirlik tahmin edicisinin daha etkin olduğu yönünde bir kanı oluşturmaktadır. Bunun yanında MCMC ile sağlanan katsayı tahminlerinin biraz daha büyük olması her iki yöntem ile tahminlerin katsayı anlamlılıklarının benzerliğini sağlamıştır. $\mathrm{Bu}$ nedenle standart hataları daha düşük olmasına rağmen model tahmini için 10 kat daha fazla süre gerektiren klasik yaklaşım olan en çok olabilirlik yöntemi yerine Bayesyen yaklaşım ile rassal etkiler MNL modelin tahmini yapmak uygulamacılar için daha uygun olmaktadır.

\section{Sonuç ve Öneriler}

Çalışmada, 2009-2012 yılları GYKA panel mikro veri setinden yararlanılması ile hanelerin yoksulluğa girme, yoksulluktan çıkma ve kronik yoksul olma durumlarının belirleyicileri analiz edilmiştir. Çalışmada en az iki dönem üst üste yoksul olan haneler kronik yoksul olarak nitelendirilmiştir. Hanelerin tekrarlı ölçümlerinin kullanılması ile dört yıllık dönem içinde bazı haneler hem yoksulluktan çıkıp hem de yoksulluğa girebilmektedir. $\mathrm{Bu}$ nedenle çalışma sonucunda yoksulluktan çıkan ve yoksulluğa giren hanelerin benzer özellikleri paylaştığı gözlenmiş ve bu haneler geçici yoksul olarak sınıflandırılmıştır.

Çalışmada dinamik yoksulluğun belirleyicileri ise rassal etkiler multinomial logit modeli ile tahmin edilmiştir. Rassal etkiler MNL modelin tahmini en çok olabilirlik yaklaşımı ve Bayesyen yaklaşım ile yapılmıştır. Rassal etkiler MNL modelin en çok olabilirlik tahmini STATA programında gllamm paketi ile sağlanmıştır. gllamm paketinde, örneklem olabilirliğini maksimize etmek için gözlenemeyen birim etkinin dağılımı üzerinden integrallerin hesaplanabilmesi amacıyla uyarlamalı kuadratik yaklaşımı kullanılmıştır. Rassal etkiler MNL modelin Bayesyen tahmini için R programında MCMC tekniğiyle GLMM'i tahmin etmek için geliştirilen MCMCglmm paketi kullanılmıştır. Her iki analiz sonucunda uyarlamalı kuadratik yaklaştırma tekniği ile elde edilen katsayıların standart hatalarının, MCMC ile elde edilen katsayıların standart hatalarından daha küçük olması klasik tahmin sonuçlarının daha kesin olduğu yönünde bir kanı oluşturmaktadır. Bunun yanında her iki yöntem ile tahminlerin katsayı anlamlılıkları benzer çıkmıştır. Bu nedenle standart hataları daha düşük olmasına rağmen model tahmini için 10 kat daha fazla süre gerektiren en çok olabilirlik 
yaklaşımı yerine MCMC ile tahmin sağlayan Bayesyen yaklaşımının daha uygun olduğu söylenebilir.

Çalışmadan elde edilen bulgular doğrultusunda yoksulluğu daha şiddetli yaşayan kesimin ve yoksulluğu dönem dönem yaşayan kesimin politika yapıcılar tarafından öğrenilmesi, iki tür yoksulluğa karşı uygulanacak politikaların belirlenmesi, geliştirilmesi ve uygulanması açısından oldukça önemli olmaktadır. Öyle ki kronik yoksul olanların yaşadıkları koşullar ve uzun süreli işsizlik, parasızlık ve bunun yanında yaşanılan gelir, eğitim, sağlık konularında dışlanmışlık hissi önce bireylerin, sonra ailenin ve son olarak toplumun refahını tehlikeye düşürmektedir. Bu açıdan kronik yoksulluğun azaltılması konusunda alınacak önlemler toplumun genel refah düzeyinde olumlu etkiler yaratacaktır.

Çalışmada elde edilen bulgulara göre yoksulluğa giren ve yoksulluktan çıkan yani geçici yoksul hanelerin yoksulluktan kurtulmaları için sosyal ve parasal yardımlar yapılması, işsizlik fonu miktarının arttırılması, mikro krediler ile iş olanaklarının arttırılması gibi gelir düzenlemelerinin sağlanması ve kayıt dışı istihdamın önüne geçilmesi gibi önlemler alınması gerekmektedir. Bunun yanında, kronik yoksul hanelerin yoksulluktan kurtulmaları için işsizlik sorununun çözülmesi, düzenli maaş ya da düzenli yardım gibi politikaların belirlenmesi ve uygulanması önem arz etmektedir. Sonuç olarak Türkiye'de gelirin daha eşit dağıtımının sağlanması, ortalama eğitim seviyesinin arttırılması, emeklilik maaşlarının iyileştirilmesi ve sağlık sisteminde yapılacak yeni uygulamalar yoksulluğun sürekliliğinin azaltılmasında etkili olacaktır.

\section{Kaynakça}

Acar, A., ve Baslevent, C. (2014). Examination of the transition of Turkish households into and out of poverty between 2007-2010. Betam Working Paper Series 15.

Alisjahbana, A. ve Yusuf, A. A. (2003). Poverty dynamics in Indonesia: panel data evidence. Working Paper in Economics and Development Studies. Padjadjaran University.

Andriopoulou, E. ve Tsakloglou, P. (2011). The determinants of poverty transitions in Europe and the role of duration dependence. IZA Discussion Paper No. 5692

Bane, M. J. ve Ellwood, D. T. (1986). Slipping into and out of poverty: The dynamics of spells. Journal of Human Resources, 21(1): 1-23.

Caglayan, E., Kosan, N. I. ve Astar, M. (2012). An empirical analysis of the determinants of household poverty in Turkey. Asian Economic And Financial Review, 2(1), 181. 
Dalgıç, B., İyidoğan, P. V. ve Güven, A. (2015). Yoksulluk ve yoksulluk geçişlerinin belirleyenleri: Türkiye örneği. Sosyoekonomi, 23(24).

Dartanto, T. ve Nurkholis. (2013). The determinants of poverty dynamics in Indonesia: evidence from panel data. Bulletin of Indonesian Economic Studies, 49(1), 61-84.

Devicienti, F. (2002). Poverty persistence in Britain: a multivariate analysis using the BHPS, 1991-1997. Journal of Economics, 9, 307-340.

Gelman, A. ve Rubin, D. B. (1992). Inference from 1terative simulation using multiple sequences. Statistical Science, 457-472.

Greene, W. H. (2003). Econometric Analysis. Pearson Edication: New Jersey. Fifty Edition.

Gürsel, S. ve Acar, A. (2015). Türkiye'de yoksulluk dinamikleri. Betam Araştırma Notu, 15/175, 29 Ocak.

Haan, P. ve Uhlendorff, A. (2006). Estimation of multinomial logit models with unobserved heterogeneity using maximum simulated likelihood. DIW Discussion Papers, No. 573.

Hadfield, J. D. (2010). MCMC Methods for multi-response generalized linear mixed models: The MCMCglmm R package. Journal of Statistical Software, 33(2), 1-22.

Hartzel, J., Agresti, A. ve Caffo, B. (2001). Multinomial logit random effects models. Statistical Modelling, 1(2), 81-102.

Hasegawa, H. ve Ueda, K. (2007). Measuring chronic and transient components of poverty: A bayesian approach. Empirical Economics, 33(3), 469-490.

Haynes, M., Western, M., Yu, L. ve Spellak, M. (2008). Analysing nominal data from a panel survey: Employment transitions of Australian women. In 103rd Annual Meeting of the American Sociological Association, 1-4.

Israeli, O. ve Weber, M. (2014). Defining Chronic Poverty: Comparing Different Approaches. Applied Economics, 46(31), 3874-3881.

Johnston, J. ve Dinardo, J. (1997). Econometrics Methods, The McGraw-Hill Companies, Inc: Printed in the United States of America.

Kızılgöl, Ö. (2009). Türkiye'de yoksulluk sorunu: Ekonometrik bir bakış. Yayınlanmamış Doktora Tezi. Dokuz Eylül Üniversitesi, Sosyal Bilimleri Enstitüsü, İzmir. 
Limanlı, Ö. (2015). Intertemporal poverty in Turkey. Procedia Economics and Finance, 30, 487-497.

Liu, X. (2015). Methods and applications of longitudinal data analysis. Elsevier.

McCulloch, N. ve Baulch, B. (1999). Distinguishing the chronically from the transitorily poor: evidence from rural Pakistan. Institute of Development Studies at the University of Sussex. IDS Working Paper, 97.

McCulloch, C. E. ve Searle, S. R. (2001). Generalized, Linear, and Mixed Models, Wiley Series in Probability and Statistics.

McFadden, D. (1973). Conditional logit analysis of qualitative choice behavior. https://eml.berkeley.edu/reprints/mcfadden/zarembka.pdf, (Erişim Tarihi: 06.02.2017).

Pettitt, A. N., Haynes, M. A., Tran, T. ve Hay, J. L. (2002). A Model for longitudinal employment status of 1mmigrants to Australia. Queensland University of Technology http://eprints.qut.edu.au/186/1/186.pdf, (Erişim Tarihi: 06.02.2017).

Rabe-Hesketh, S., Skrondal, A. ve Pickles, A. (2002), Reliable estimation of generalized linear mixed models using adaptive quadrature. The Stata Journal, 2(1), 1-21.

Ravallion, M. (1988). Expected poverty under risk-1nduced welfare variability. The Economic Journal, 1171-1182.

Ravallion, M., van de Walle, D. ve Gautam, M. (1995). Testing a social safety net. Journal of Public Economics, 57, 175-199

Şeker, S. D. (2011). The dynamics of poverty in Turkey. Yayınlanmamış Doktora Tezi, Ortadoğu Teknik Üniversitesi İktisat Bölümü, Ankara.

Şeker, S. D. ve Dayığlu, M. (2014). Poverty dynamics in Turkey. Review of Income and Wealth, 61(3), 477-493.

The Chronic Poverty 2004-2005 http://www.chronicpoverty.org/uploads/publication_files/CPR1_ReportFul 1.pdf, (Erişim Tarihi: 21.10.2016).

TÜIKK (2016), Gelir ve Yaşam Koşulları İstatistikleri, www.tüik.gov.tr, (Erişim Tarihi: 21.01.2016). 
Walelign, S. Z., Charlery, L., Smith-Hall, C., Chhetri, B. B. K. ve Larsen, H. O. (2016). Environmental income 1mproves household-level poverty assessments and dynamics. Forest Policy and Economics, 71, 23-35.

Yaqub, S. (2000). Poverty dynamics in developing countries. Brighton: Institute of Development Studies, Vol. 16. 


\title{
Bayesian And Classic Approaches for Multinomial Logit Model with Random Effects: The Case of Dynamic Poverty in Turkey
}

\author{
Extended Abstract
}

\section{Introduction}

It is important to examine the dynamic structure of poverty, as poverty can vary according to differences both in the welfare level and situation at a point in time. Taking into account the dynamic structure of the concept of poverty, the concepts of chronic and transient poverty have emerged. According to Bane and Ellwood (1986), households whose household income is less than the poverty line at more than or half of the time analyzed are chronic poor. Households whose household income is less than the poverty line at less than half of the time analyzed are transient poor.

This study investigates the determinants of poverty outflow, transient poverty and chronic poverty in Turkey using Turkish Statistical Institute, Income and Living Conditions Survey (SILC) panel micro data for the period of 2009-2012 by applying the multinomial logit model with random effects.

\section{Method}

In this study, Multinomial logit model (MNL) developed by McFadden(1973) considered as the multinomial logit model with random effects to take into account the correlation between repeated observations of households. Households are divided into four categories as non-poor (1), poverty outflow (2), transitory poverty (3) and chronic poverty (4) as a dependent variable. The non-poor (1) is considered as the reference category for the prediction of the model. The random effects MNL model can be expressed as

$$
\pi_{i t j}=P\left(Y_{i t}=j / X_{i t}, \alpha_{i}\right)=\frac{\exp \left(X_{i t} \beta_{j}+\alpha_{i j}\right)}{\sum_{k=1}^{j} \exp \left(X_{i t} \beta_{j}+\alpha_{i k}\right)} j=1,2,3,4 ; t=2010,2011,2012
$$

where $X_{i t}$ is household's properties and $P\left(Y_{i t}=j / X_{i t}\right)$ is possibility of being poverty of household $i$ in time $t$ (Haan and Uhlendorff, 2006; Haynes vd.,2008).

In this study, the multinomial logit model with random effects were estimated both utilizing Bayesian and classic approaches.

\section{Results and Discussion}

According to the findings obtained in the study, the age of the head of the household has a positive effect on both transient poverty and chronic poverty compared to the non-poor, while the squared of age of the head of the household has a negative effect. This finding shows that, possibility of being both transient and chronic poor of households increases as the age of the household head increases, but after a certain age, the possibility of being poor of households decreases as the age of the household head increases. In addition, being a female household head has a negative effect on both transient and chronic poverty while being a married household head has a positive effect on chronic poverty.

The findings show that, possibility of being both transient poor and chronic poor are decreases as the education level of the household head increases. It is a fact that the household head has a wage and salary has a negative effect on the possibility of being transient and chronic poor, compared to the non-poor. This finding indicates that the household head receiving a regular salary reduces the 
risk of poverty of the household. Being a retired household head has a negative effect on chronic poor. According to this finding, households who are retired are less likely to take part in the poverty-stricken population, such as chronic poor, due to their regular revenues. Probability of being transient and chronic poor of elderly, disabled or inoperable head of households is also positive. Changing the job in the last 12 months of household head influences the possibility of the household moving out of poverty. According to the single households, the households with dependent children and those without dependent children are at higher risk of becoming transient poor and chronic poor.

The coefficients of income variable are negative and statistically significant in two models, as expected. So, household revenues significantly reduce the risk of being transient and chronic poor of households.

\section{Conclusion}

According to the results, although similar results were obtained with both approaches, the estimation period of Bayesian approach was ten times shorter than the classical approach. The results show that the features of the household's head and household have a different impact both on the transient poverty and chronic poverty of household.

According to the findings obtained in the study, it is necessary to provide income arrangements such as social and financial aid to increase the income of the temporary poor households. Besides, it is important to increase the amount of unemployment fund and provide employment opportunities with micro loans. As a conclusion, policies such as regular salary or regular aid should be identified and implemented in order to get rid out of poverty for chronic poor households. 